\title{
Managing Growth to Achieve Efficient Coordination in Large Groups
}

\author{
By Roberto A. Weber*
}

\begin{abstract}
Previous experiments using the minimum-effort coordination game reveal a striking regularity-large groups never coordinate efficiently. Given the frequency with which large real-world groups, such as firms, face similarly difficult coordination problems, this poses an important question: Why do we observe large, successfully coordinated groups in the real world when they are so difficult to create in the laboratory? This paper presents one reason. The experiments show that, even though efficient coordination does not occur in groups that start off large, efficiently coordinated large groups can be "grown." By starting with small groups that find it easier to coordinate, we can add entrants-who are aware of the group's history-to create efficiently coordinated large groups. This represents the first experimental demonstration of large groups tacitly coordinated at high levels of efficiency. (JEL C72, C92, M53)
\end{abstract}

Coordination is an important problem for economics and organization (Ronald H. Coase, 1937; James M. March and Herbert A. Simon, 1958; Thomas C. Schelling, 1960; Kenneth J. Arrow, 1974; Russell W. Cooper, 1999). Tacit coordination deals with situations in which economic actors attempt to match the actions of others without knowing what these others will do and without an agreement about what to do. ${ }^{1}$

This paper addresses the difficulty of tacit coordination in large groups. Considerable experimental evidence-mostly from a game known as the minimum-effort (or "weak-link") coordination game-shows that group size has

* Department of Social and Decision Sciences, Carnegie Mellon University, Pittsburgh, PA 15213 (e-mail: rweber@andrew.cmu.edu). Thanks to Colin Camerer, David Grether, Richard McKelvey, Tom Palfrey, John Patty, various seminar participants, and two anonymous referees for valuable comments and suggestions. Thanks to Alex Markle and Scott Rick for help in conducting the experiments. This research was funded by the Russell Sage Foundation Behavioral Economics Small Grant Program and by Carnegie Mellon University.

${ }^{1}$ Examples of coordination problems include buyers or sellers searching for a market, workers with complementary production tasks, or consumers purchasing products with network externalities. In game-theoretic terms, coordination problems arise when there are multiple equilibria, and players must tacitly resolve which one to play. a strong effect on the ability of groups to coordinate (e.g., John B. Van Huyck et al., 1990; Weber et al., 2001). Large groups of people who cannot speak to one another almost never coordinate successfully, and repetition alone does not solve the problem. ${ }^{2}$

This observation is inconsistent, however, with the real world, where we observe groups much larger than those in experiments-such as firms and communities-where coordination plays a crucial role, but where these large groups have managed to coordinate successfully. This observation of large, efficiently coordinated groups outside the laboratory creates a puzzle: If "large" laboratory groups cannot coordinate efficiently, how do large communities and firms often do so?

This paper demonstrates that the ability of large groups to coordinate successfully can be critically affected by the group's growth process. As previous research shows, coordination is easy in small groups. Therefore, members of a small group, such as the founding members of a firm, do not face substantial difficulty in co-

\footnotetext{
${ }^{2}$ In fact, even with communication, large-group coordination is still difficult (see, for instance, Weber et al., 2001; Ananish Chaudhuri et al., 2001). Gary Charness (2000) shows that communication helps in small groups.
} 
TABle 1-Payoffs (in Dollars) For Minimum-EFfort GAME

\begin{tabular}{|c|c|c|c|c|c|c|c|c|}
\hline & & \multicolumn{7}{|c|}{ Minimum choice of all players } \\
\hline & & 7 & 6 & 5 & 4 & 3 & 2 & 1 \\
\hline \multirow[t]{7}{*}{ Player's choice } & 7 & 0.90 & 0.70 & 0.50 & 0.30 & 0.10 & -0.10 & -0.30 \\
\hline & 6 & & 0.80 & 0.60 & 0.40 & 0.20 & 0.00 & -0.20 \\
\hline & 5 & & & 0.70 & 0.50 & 0.30 & 0.10 & -0.10 \\
\hline & 4 & & & & 0.60 & 0.40 & 0.20 & 0.00 \\
\hline & 3 & & & & & 0.50 & 0.30 & 0.10 \\
\hline & 2 & & & & & & 0.40 & 0.20 \\
\hline & 1 & & & & & & & 0.30 \\
\hline
\end{tabular}

ordinating activity efficiently. Once they have done so, they can establish a set of selfreinforcing rules or norms governing what actions are appropriate, and these allow the group to continue to coordinate activity successfully. As the group grows, entrants' exposure to these norms allows these entrants to be aware of the appropriate behavior, and creates an expectation for everyone in the group of what everyone else (including the entrants) will do. Thus, by coordinating efficiently as a small group, growing slowly, and exposing entrants to the group's previous norms, a group can become large and efficiently coordinated.

The rest of this paper demonstrates the influence of growth on tacit coordination using an experiment involving the minimum-effort coordination game. The experiment is motivated by a simple model-discussed briefly later in this paper-which shows why growth should work when entrants are exposed to the group's history. In the experiment, efficiently coordinated large groups, which are impossible to obtain when a group starts out at a large size, are "grown" in the laboratory by starting with small groups and adding a few entrants at a time who are exposed to the group's history. This paper produces the only laboratory demonstration of the regular occurrence of efficient tacit coordination among large groups. The experiment also reveals, however, that the ability of entrants to observe the group's history is crucial-if they are not aware of what incumbent members did in the past, coordination failure results.

\section{The Minimum-Effort Coordination Game}

The minimum-effort, or weak-link, coordination game was first studied experimentally by
Van Huyck et al. (1990). ${ }^{3}$ In the game-which is a seven-effort-level version of the stag hunt game (see Crawford, 1995) $-n$ players choose from a set of integers that can be thought of as orderable strategies such as effort or contribution levels. Every player's payoff is a function of her choice and the minimum choice of all $n$ players (thus the term "weak-link," since every player's payoff is partially determined by the lowest choice in the group). Table 1 presents the payoff to each player as a function of her choice and the minimum choice. ${ }^{4}$

When everyone makes the same choice and therefore receives the same payoff (represented by cells along the diagonal), the outcome is one of the game's seven pure-strategy Nash equilibria. The equilibria differ because those corresponding to higher choices also yield higher payoffs. Therefore, "more efficient" coordination corresponds to all players making higher choices in equilibrium and the Pareto-optimal (or efficient) equilibrium results when all players select the highest choice, 7 , and receive $\$ 0.90$.

Since all symmetric outcomes, including the efficient one, are equilibria, this game does not have the incentive problem present in the prisoner's dilemma. Nonetheless, the efficient equilibrium may not be easy to achieve because players are faced with strategic uncertainty. Everyone may recognize the efficient equilibrium,

\footnotetext{
${ }^{3}$ See also Jack Hirshleifer (1983) for an early theoretical discussion of the problem underlying the game.

${ }^{4}$ The game in Table 1 is the same as Game A in Van Huyck et al. (1990), except every payoff is lower by $\$ 0.40$. Of course, real payoffs also differ due to differences in experimental location and time. However, experiments using the two sets of payoffs produce similar small versus large group results.
} 
Table 2-Distributions of Fifth-Period Group Minima in Various 7-Action Minimum-Effort Studies $(1=$ inefficient $; 7=$ efficient $)$

\begin{tabular}{|c|c|c|c|c|c|c|c|c|c|}
\hline \multicolumn{7}{|c|}{ Minimum choice in fifth period } & \multirow{2}{*}{$\begin{array}{c}\text { Group } \\
\text { size }\end{array}$} & \multirow{2}{*}{$\begin{array}{l}\text { Number of } \\
\text { groups }\end{array}$} & \multirow[b]{2}{*}{ Source } \\
\hline 7 & 6 & 5 & 4 & 3 & 2 & 1 & & & \\
\hline $86 \%$ & $3 \%$ & $3 \%$ & $3 \%$ & $0 \%$ & $0 \%$ & $5 \%$ & 2 & 37 & VHBB, CK \\
\hline $18 \%$ & $4 \%$ & $0 \%$ & $11 \%$ & $15 \%$ & $15 \%$ & $37 \%$ & 3 & 27 & $\mathrm{KC}, \mathrm{CK}$ \\
\hline $0 \%$ & $0 \%$ & $0 \%$ & $0 \%$ & $10 \%$ & $10 \%$ & $80 \%$ & 6 & 10 & $\mathrm{KC}$ \\
\hline $0 \%$ & $0 \%$ & $0 \%$ & $0 \%$ & $0 \%$ & $0 \%$ & $100 \%$ & 8 & 5 & CSS \\
\hline $0 \%$ & $0 \%$ & $0 \%$ & $0 \%$ & $0 \%$ & $0 \%$ & $100 \%$ & 9 & 2 & $\mathrm{CC}$ \\
\hline $0 \%$ & $0 \%$ & $0 \%$ & $0 \%$ & $0 \%$ & $0 \%$ & $100 \%$ & $14-16$ & 7 & VHBB \\
\hline
\end{tabular}

Sources: Van Huyck et al., 1990 (VHBB); Camerer and Knez, 2000 (CK); Knez and Camerer, 1994 (KC); Gerard P. Cachon and Camerer, 1996 (CC); Chaudhuri et al., 2001 (CSS).

but may be unsure of what others will do. Therefore, players may choose something other than 7 , particularly when they think it is likely that someone else will choose something other than 7. Simply being unsure about what others will do may lead to choices other than 7 .

Previous experiments with minimum-effort coordination games established clear regularities. Tacit coordination on the efficient equilibrium is impossible for large groups. Of the seven sessions initially conducted by Van Huyck et al. (1990) with groups of size 14 to 16, the minimum in all sessions after the third period was the lowest possible choice. For small groups $(n=2)$ playing in fixed pairs, coordination on the efficient equilibrium was much easier-it was reached in 12 of 14 (86 percent) of the groups (a result replicated by Colin F. Camerer and Marc Knez, 2000). Table 2 summarizes the distributions of fifth-period minima in several different experiments, all using variants of the Van Huyck et al. game in which players choose integers from 1 to 7 , and choosing 7 is efficient.

The effect of group size could hardly be stronger. Subjects in a group size of 2 are almost assured to coordinate on the efficient equilibrium, while subjects in larger groups (six or more) are almost assured to converge to the least efficient outcome in which at least one player chooses 1 . Thus, there is a strong negative relationship between a group's size and the ability of its members to coordinate efficiently. ${ }^{5}$

\footnotetext{
${ }^{5}$ Once these groups reached the inefficient outcome, they were not able subsequently to increase the minimum.
}

\section{Growing Efficient Coordination}

Given the link between coordination in minimum-effort games and coordination problems faced by such real-world groups as firms (e.g., Camerer and Knez, 1997; Ashish Nanda, 1997; Jody H. Gittell, 2001), the work above suggests an impossibility to regularly obtaining efficient coordination in large groups outside the laboratory. This is inconsistent, however, with the observation that there exist efficiently coordinated real-world groups. To see how we might resolve this apparent inconsistency, we need to begin by recognizing that few large groups start off at a large size. Most groups, in fact, begin small, when solving coordination problems is easier according to the experimental literature noted above. Once successfully coordinated, then, these groups might be able to remain coordinated as entrants are added-particularly if the entrants are aware of the group's previous success.

Using a simple dynamic model based on Vincent P. Crawford's (1995) model of adaptive dynamics in order-statistic coordination games (which include minimum-effort games), Weber (2005) shows how growth can produce large, efficiently coordinated groups (see, also, Weber, 2000). The model assumes that player $i$ 's discrete action in period $t\left(x_{i t}\right)$ is determined by a continuous latent strategy variable $\left(a_{i t}\right)$ (for

This result has also been replicated using different versions of the game (e.g., Weber et al., 2001). A few studies show that changing incentives improves coordination for groups of seven to eight players (Siegfried Berninghaus and Karl Ehrhart, 1998; Gary Bornstein et al., 2002). 
instance, by rounding the latent variable to the nearest discrete action). Initial choices are determined by a common belief and an idiosyncratic stochastic term measuring strategic uncertainty. ${ }^{6}$ When group size is fixed, subsequent choices are determined by a simple linear adjustment from the player's own previous choice toward the previous minimum, as well as by a mean zero error term representing strategic uncertainty. ${ }^{7}$ The variance of the error term decreases with experience, reflecting the resolution of strategic uncertainty. ${ }^{8}$

To include the possibility of growing groups, the model defines a "growth path" as a sequence of weakly increasing sets of players. The set of players in any period $t$ includes three possible kinds of players: incumbents (those who played the game in period $t-1$ ), informed entrants (those who did not play the game in period $t-$ 1 , but observed the entire sequence of group minima), and uninformed entrants (those who did not play the game in period $t-1$, and did not observe any of the previous minima). The composition of the group in any period is common knowledge.

Incumbent players' dynamic adjustment occurs in the same manner as in the model without growth (as in footnote 7). Uninformed entrants' choices are determined by a draw from the initial distribution of choices (as in footnote 6). Informed entrants also generate a draw from the initial distribution, but then perform one iteration of the dynamic adjustment process in the direction of the minimum in the last period..$^{9}$

One final, and important, difference between the models without and with growth is that, in the latter, the change in the variance of the error term from period $t-1$ to period $t$ depends on the composition of the group in period $t$. Spe-

\footnotetext{
${ }^{6}$ Specifically, $a_{i 1}=\alpha_{0}+\varepsilon_{i 1}$, where $\alpha_{0}$ represents a common belief and $\varepsilon_{i 1}$ is distributed normally with mean zero and variance $\sigma_{1}^{2}>0$. Thus, players' initial choices are i.i.d. draws from a common distribution that is independent of group size.

${ }^{7}$ Player $i$ 's latent strategy in period $t$ is given by $a_{i t}=$ $(1-\beta) x_{i t-1}+\beta y_{t-1}+\varepsilon_{i t}$, where $y_{t-1}$ is the minimum in period $t-1$ and $0<\beta<1$. The $\varepsilon_{i t}$ are distributed normally, with mean zero and variance $\sigma_{t}^{2}$.

${ }^{8}$ Specifically $\sigma_{t}^{2}=k \sigma_{t-1}^{2}$, where $0 \leq k<1$.

${ }^{9}$ That is, an informed entrant's choice is given by $a_{i t}=$ $(1-\beta) x_{i 1}+\beta y_{t-1}+\varepsilon_{i t}$
}

cifically, if all of the players are aware of the full history of minima (i.e., the group consists only of incumbents and informed entrants), then the variance decreases from the previous period (as in footnote 8). If, however, there are any uninformed entrants in period $t$, the variance of the error term is higher than it was in period $t-$ 1 for all players. This increase in variance captures the increased strategic uncertainty produced by the entry of players unaware of the group's history.

Weber (2005) shows the following result for the model above: for any two groups such that one group maintains a constant size and the other group starts small and grows to that size by adding only informed entrants, both choices and minima in any period will be stochastically higher in the grown group than in the group of constant size. ${ }^{10,11}$ The intuition behind the result is simple. In the first period, the smaller group obtains a (stochastically) higher minimum. In subsequent periods, three conditions ensure that the grown group maintains this advantage. First, the linear adjustment process never moves downward "faster" for players in the grown group than for players in the fixedsize group. Second, as long as entrants are informed, the variance on the term measuring strategic uncertainty is never greater in the grown group than in the fixed-size group. And, third, the number of players is never greater in the grown group than in the fixed-size group. These last two conditions ensure that the stochastic component of choice never decreases the minimum in the grown group faster than in the fixed-size group. ${ }^{12}$

Importantly, the result above does not hold if

\footnotetext{
${ }^{10}$ The term "stochastically higher" refers to an upward shift in the probability distribution of the variable, in the manner of first-order stochastic dominance (cf. Crawford, 1995).

${ }^{11}$ Note that this does not imply "lock in" on equilibria above the least efficient. However, all that is necessary to allow such "lock in" is that the variance of the $\varepsilon_{i t}$ decrease to zero (i.e., as when $k=0$ in footnote 8 ).

${ }^{12}$ A second result shows that, for any two groups that both grow only by adding informed entrants, if one group grows more slowly than the other (meaning that it starts off smaller, is never larger, and never adds more people in a period), the choices and minima will be stochastically higher in the more slowly grown group.
} 
groups grow by adding uninformed entrants. This is because the second condition above no longer holds. The increase in strategic uncertainty due to the introduction of uninformed entrants in a period increases the variance of choices and stochastically decreases the minimum in that period, meaning that the group that starts small (with a higher minimum) can lose its advantage when uninformed entrants are added.

The result above implies a clear prescription for alleviating large-group coordination failure. By starting at a small size and adding only entrants who are aware of the group's history, one should be able to produce a group of any finite size with higher minima, on average, than groups that start off at the large size. The ability of new entrants to observe the group's history, however, is critical, since it underlies the decrease in strategic uncertainty. This implies that growth without such "exposure" of new entrants should not be successful in producing large groups with higher minima. The experiment in the next section directly tests the effectiveness of growth with and without such exposure.

\section{Growing Efficient Coordination in the Laboratory}

This experiment tests the hypothesis that growth, coupled with exposure of entrants to the group's history, produces groups with higher minima than control groups that start off at a large size. The experiment also tests the hypothesis that growth without exposure of entrants to the group's history will not produce higher minima. The results are clear: while none of the control groups or "no-history" groups manages to coordinate on a minimum above one, several grown groups manage to coordinate at higher levels of efficiency, including on the highest possible minimum.

\section{A. Experimental Design}

This experiment explored whether a slow, steady growth rate determined by the experimenter could create large groups coordinated more efficiently than fixed-size large groups. In each session of the experiment, a group of 12 students (at Stanford University, the University of California at Santa Cruz, or Carnegie Mellon University) were assembled in one room, assigned participant numbers from 1 through 12 , and presented the game in Table $1 .{ }^{13}$ Instructions were read aloud and, before starting the game, participants answered several questions to ensure their comprehension of the instructions and the game. At the end of the experiment, subjects were anonymously paid their earnings in cash.

There were three kinds of sessions. In control sessions, no mention was made of growth and a group of 12 subjects played the game for 12 periods. In two kinds of growth sessions, the group of subjects playing the game grew in size from 2 to 12 .

Two growth treatments tested the effect of entrants' awareness of the group's history. In the history condition, entrants observed the group's history (the minima in all previous periods) and this was common knowledge. In the no-history condition, entrants were not aware of any of the previous minima.

Each of the growth sessions consisted of 22 periods. In the first several periods, only participants 1 and 2 played the game, while the other subjects sat quietly (history condition) or were in another room (no-history condition). Participants were told that they would receive a fixed, positive, "fair" amount for periods in which they were not playing the game, but that the exact amount would not be revealed until the end of the experiment. ${ }^{14}$ In each period, participating subjects recorded a number from 1 to 7 (indicating the contribution time for their section of the report) on a piece of paper and

\footnotetext{
${ }^{13}$ The game was framed in the context of a report completion as in Weber et al. (2001). Subjects were also given Table 1 with an explanation of the payoffs. Weber et al. (2001) found no difference in behavior with and without such context.

14 This was done because of the concern that announcing the per-period amount might create a focal point that could influence choices. Subjects were told that they were not informed of the amount because "we do not want this to influence your choices." To ensure that they believed the amount was fixed-and not dependent on what happened in the experiment-the experimenter placed a large envelope at the front of the room and told subjects that the amount was written on a sheet inside the envelope. This sheet was shown to subjects at the end of the experiment.
} 


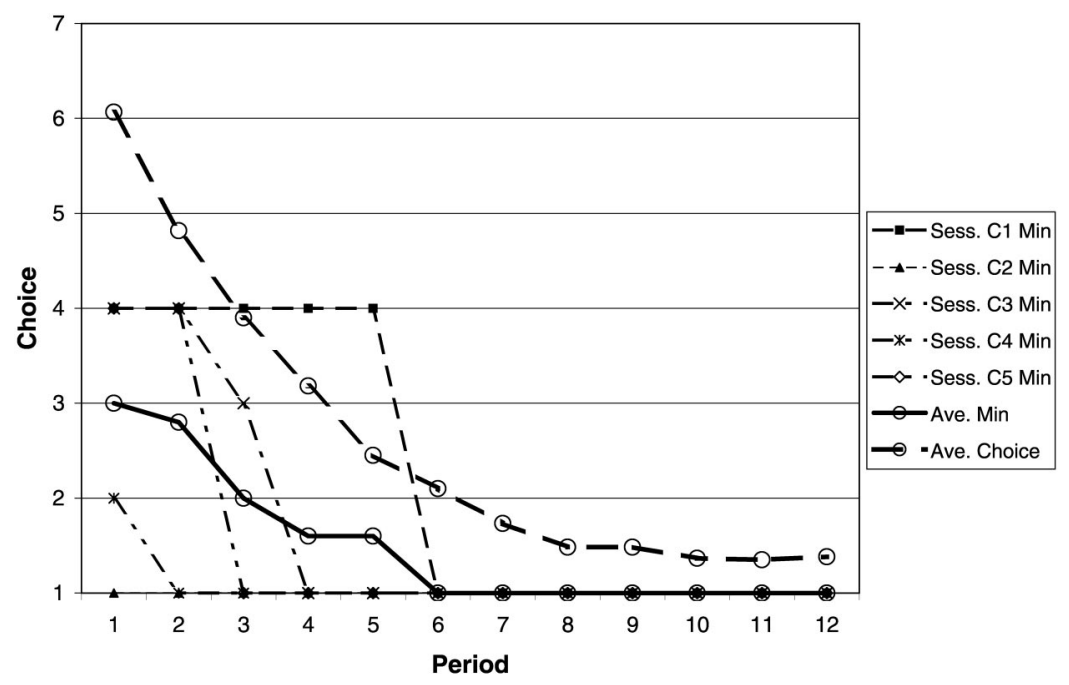

Figure 1. Period Minima in Control Sessions

handed it to the experimenter. ${ }^{15}$ The experimenter then calculated the minimum, wrote this number on the board, asked subjects to calculate their payoffs, and checked to make sure that they had done so correctly. ${ }^{16}$ Before proceeding to the next round, the experimenter erased outcome information from the board.

${ }^{15}$ To prevent players from knowing which others were participating in the history condition, all players handed in slips of paper (nonparticipants checked a box indicating they were not playing). In the no-history condition, subjects knew the participant number of subjects 3 to 12 since they entered the room once they were added (though participants already in the group were seated facing away from the door so that they could not look at or make eye contact with the entrant). The history and control sessions (with anonymity) were designed and conducted before deciding to run the no-history condition (where anonymity is difficult) at the suggestion of two anonymous reviewers. It would have been possible to maintain anonymity in the no-history sessions by, for instance, using a code to report the group's history or reporting history via private messages, but both these procedures eliminate common knowledge of outcomes among those in the group.

${ }^{16}$ In all conditions, the action chosen by any participant was anonymous - except for choices by participants 1 and 2 in the no-history condition, where a subject choosing a higher number could infer both the identity and the choice of the other subject. Since the results for two-person groups are similar in both the history and no-history conditions, this appears not to have influenced behavior.
At various preannounced and commonly known periods, other participants joined the group of those actively playing the game. For example, in one of the sessions, a third participant (3) was added in period 7 , joining the first two participants (1 and 2), who continued to participate. In the no-history condition, the entrant was brought in from the other room. Participant numbers of those playing the game in a period were written on the board at the beginning of the period. In each session, a schedule of such additions (a "growth path") was handed to all subjects at the beginning of the experiment. Subjects all knew the predetermined growth path. In all growth paths, 12 subjects were participating by the last few periods.

\section{B. Results: Control Sessions}

Five control sessions $(n=60)$ were conducted using undergraduates at Stanford University, California Institute of Technology, and Carnegie Mellon University. The results are reported in Figure 1, which presents the minimum choice across all 12 periods for each session. ${ }^{17}$ In addition, the two thicker lines present the

17 The dataset is available at http://www.e-aer.org/data/ mar06_data_20020652.zip. 


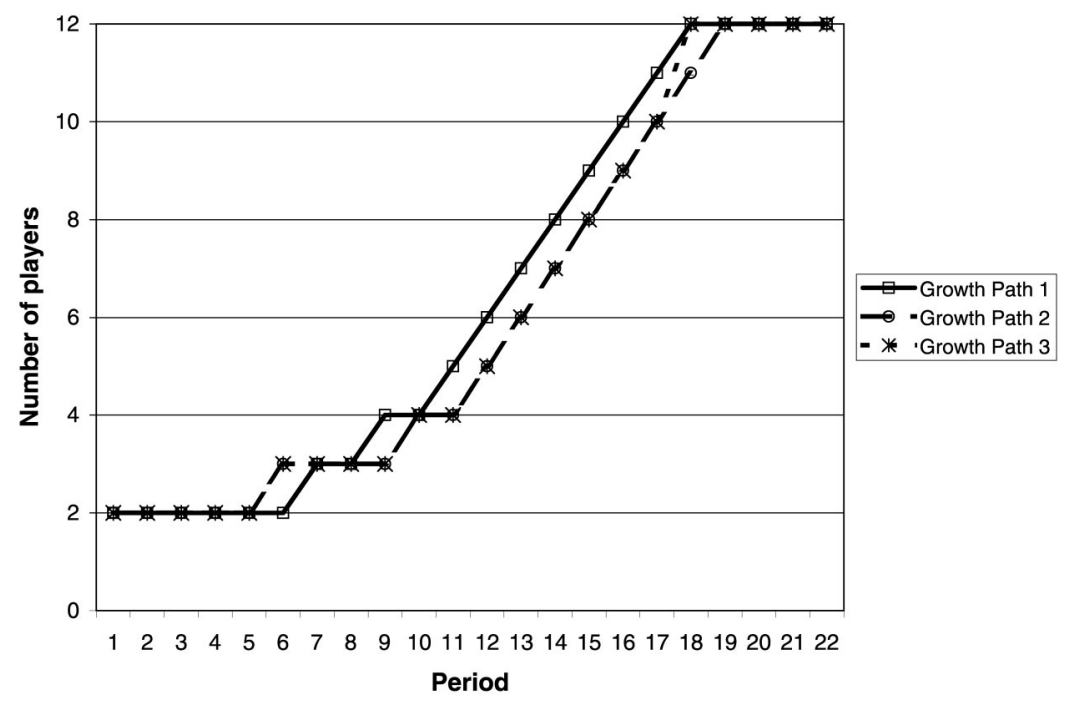

Figure 2. Predetermined Growth Paths

average of the session minima and the average choice across all sessions.

Overall, the results replicate previous findings on large groups playing the minimumeffort coordination game. The minimum fell to 1 in all five control groups. Both the average choice and the average of the minima consistently decreased and ended up at or near 1 by the final periods.

\section{Results: Growth Sessions}

Twelve sessions with predetermined growth paths $(n=144)$ were conducted at Stanford University (sessions 1 to 4), University of California, Santa Cruz (sessions 5 to 7), and Carnegie Mellon University (sessions 8 to 12). Of these, nine sessions (1 to 9) were in the history condition, while three (10 to 12 ) were in the no-history condition.

Figure 2 shows the three growth paths used in the experiment. The growth paths were designed first to allow the establishment of successful coordination in a two-person group (by allowing several periods before adding more participants) and to then add players in a slow and regular manner. Thus, with one exception (the last two players added in growth path 3), the growth paths add only one player at a time.

Figures $3 \mathrm{~A}$ through $3 \mathrm{C}$ present the minimum choices for sessions 1 through 9 (history) while
Figure 3D presents the minimum choices for sessions 10 through 12 (no history). Each figure also presents the corresponding growth path. The marker-less solid line in each figure shows the growth path (measured on the left vertical axis), while each of the remaining lines presents the minima in a particular session (measured on the right vertical axis).

Table 3 presents summary statistics of the minima in each session for varying ranges of group size. The second through sixth columns contain the average and median group minima for the periods in which the group size was within a particular range (for instance, the second column corresponds to a group size of 2). The final column presents the minimum in the first period in which that group reached a size of 12 .

An examination of behavior in individual sessions reveals several behavioral regularities. First, the small groups were able to coordinate efficiently in both history and no-history sessions. In all but one of the sessions, the group of size 2 coordinated on a minimum of 7 for at least two consecutive periods prior to growing. The remaining group (session 7) coordinated on a high level of efficiency (minimum $=6$ ).

A second observation is that growth did not always work, even with history. In three history sessions $(1,3$, and 6$)$ the minimum by the first 


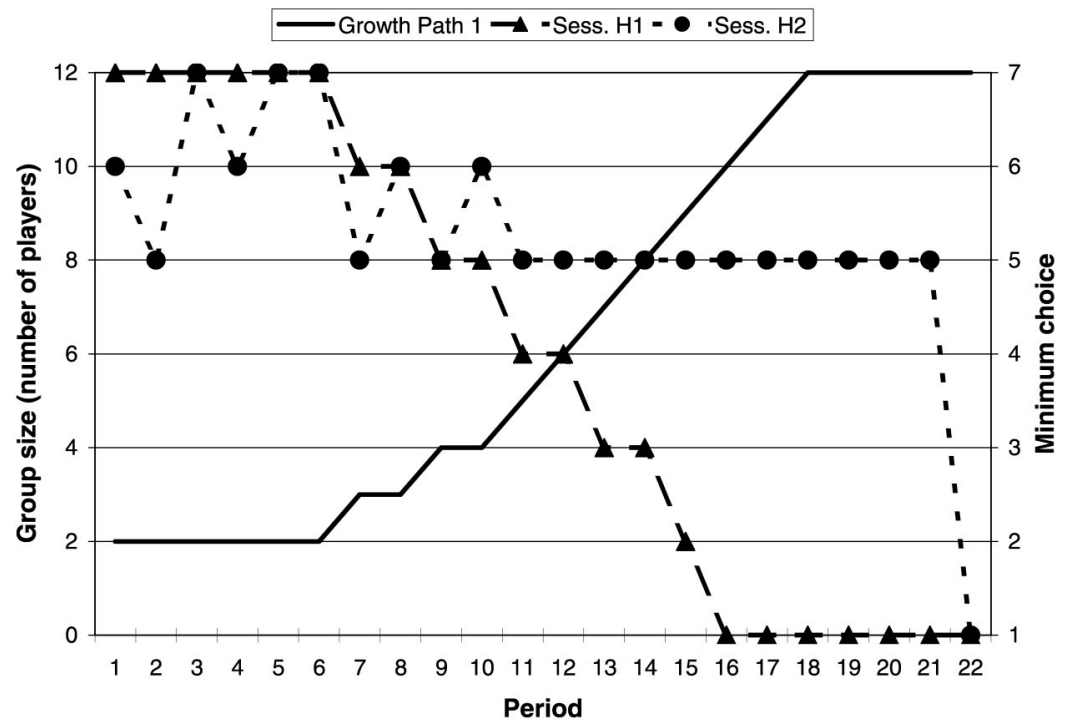

Figure 3A. Growth Path 1 and Period Minima for Sessions 1 and 2 (History)

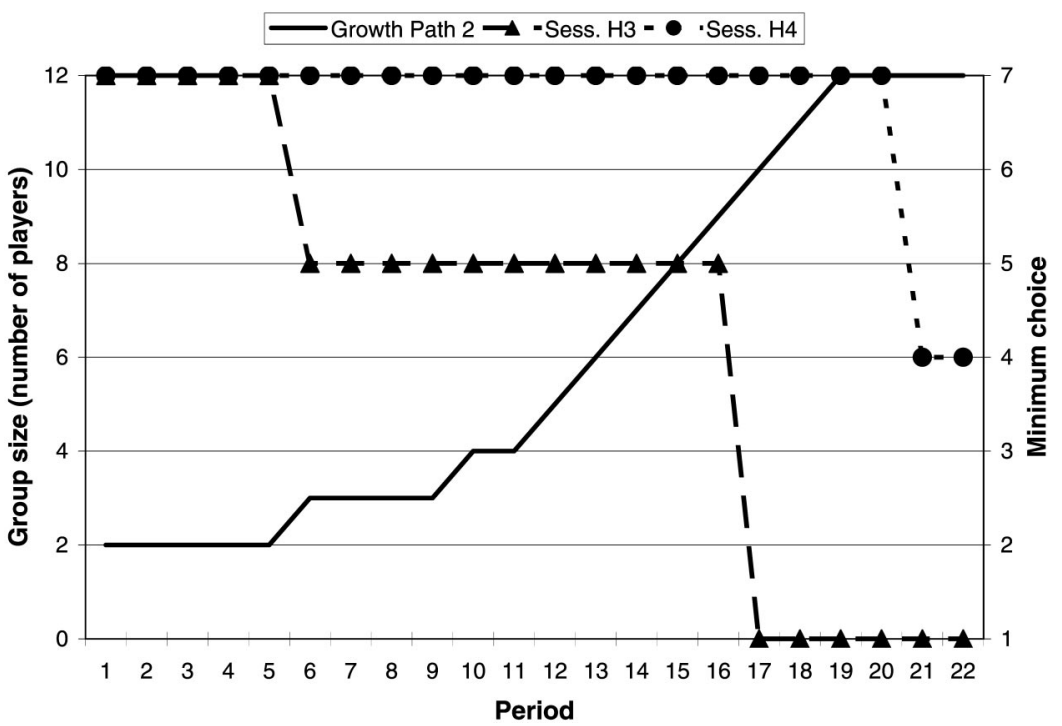

Figure 3B. Growth Path 2 and Period Minima for Sessions 3 and 4 (History)

period in which the group played as a 12-person group was 1 . Therefore, growth did not always produce efficiently coordinated groups, even with growth paths designed to do so.

An equally strong regularity, however, is that growth often produced large groups coordinated at high levels of efficiency. In three sessions (4,
8, and 9), the minimum remained at 7 throughout the growth process, and these groups obtained a minimum of 7 in at least two periods at a group size of 12 (recall that control 12-person groups never manage to coordinate on a minimum of 7 in any period). In another session (2), the minimum remained at 5 throughout the 


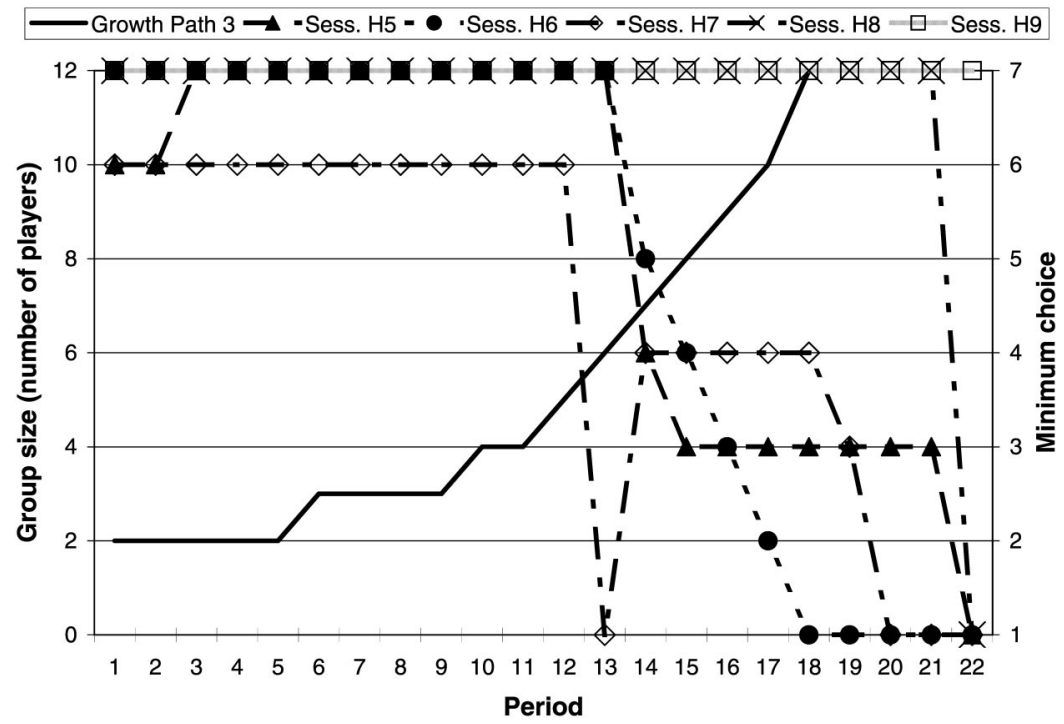

Figure 3C. Growth Path 3 and Period Minima for Sessions 5 through 9 (History)

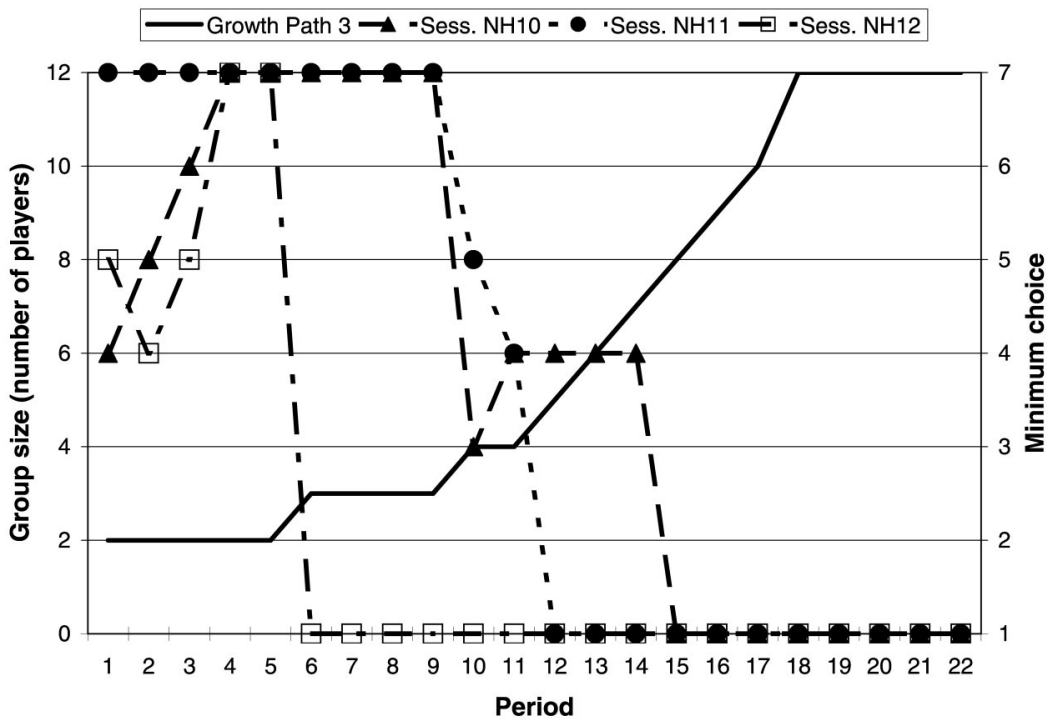

Figure 3D. Growth Path 3 and Period Minima for Sessions 10 through 12 (No History)

growth process (falling only in the last period), ${ }^{18}$ while in another session (5) it did not fall

${ }^{18}$ In several sessions $(2,4,5$, and 8$)$ the minimum in one of the final two periods fell to a lower value than that at which the group was coordinated previously. This "end of experiment effect" frequently occurs in these games and results from a few subjects changing their choices in the final periods (perhaps to do better that others, or perhaps below 3 as the group grew. In five out of nine sessions in the history condition, groups played

because they believe that others will do so). While this phenomenon is interesting, this paper is not principally concerned with what occurs in the final periods (after growth is completed), but rather with coordination during and immediately after growth. 
Table 3-Average Minima (Medians) by Session for Ranges of Group Size

\begin{tabular}{|c|c|c|c|c|c|c|}
\hline & \multicolumn{5}{|c|}{ Growth path 1: Group size (number of periods at that size) } & \multirow{2}{*}{$\begin{array}{c}\text { First } n=12 \\
\text { minimum }\end{array}$} \\
\hline & $2(6)$ & $3(2)$ & $4-6(4)$ & $7-11(5)$ & $12(5)$ & \\
\hline Session $1(\mathrm{~h})$ & $7.0(7)$ & $6.0(6)$ & $4.5(4.5)$ & $2.0(2)$ & $1.0(1)$ & 1 \\
\hline Session $2(\mathrm{~h})$ & $6.3(6.5)$ & $5.5(5.5)$ & $5.3(5)$ & $5.0(5)$ & $4.2(5)$ & 5 \\
\hline
\end{tabular}

Growth path 2: Group size (number of periods at that size)

\begin{tabular}{lcccccc} 
& $2(5)$ & $3(4)$ & $4-6(4)$ & $7-11(5)$ & $12(4)$ & \\
\cline { 2 - 6 } & $7.0(7)$ & $5.0(5)$ & $5.0(5)$ & $3.4(5)$ & $1.0(1)$ & 1 \\
Session 3 (h) & $7.0(7)$ & $7.0(7)$ & $7.0(7)$ & $7.0(7)$ & $5.5(5.5)$ & 7 \\
\hline
\end{tabular}

Growth path 3: Group size (number of periods at that size)

\begin{tabular}{lllllll} 
& $2(5)$ & $3(4)$ & $4-6(4)$ & $7-10(4)$ & $12(5)$ \\
\hline Session 5 (h) & $6.6(7)$ & $7.0(7)$ & $7.0(7)$ & $3.3(3)$ & $2.6(3)$ & 3 \\
Session 6 (h) & $7.0(7)$ & $7.0(7)$ & $7.0(7)$ & $3.5(3.5)$ & $1.0(1)$ & 1 \\
Session 7 (h) & $6.0(6)$ & $6.0(6)$ & $4.8(6)$ & $4.0(4)$ & $2.0(1)$ & 4 \\
Session 8 (h) & $7.0(7)$ & $7.0(7)$ & $7.0(7)$ & $7.0(7)$ & $5.8(7)$ & 7 \\
Session 9 (h) & $7.0(7)$ & $7.0(7)$ & $7.0(7)$ & $7.0(7)$ & $7.0(7)$ & 7 \\
\hline Session 10 (nh) & $5.8(6)$ & $7.0(7)$ & $3.8(4)$ & $1.8(1)$ & $1.0(1)$ & 1 \\
Session 11 (nh) & $7.0(7)$ & $7.0(7)$ & $2.8(2.5)$ & $1.0(1)$ & $1.0(1)$ & 1 \\
Session 12 (nh) & $5.6(6)$ & $1.0(1)$ & $1.0(1)$ & $1.0(1)$ & $1.0(1)$ & 1 \\
\hline
\end{tabular}

a minimum of three or higher for at least two periods at a size of 12 , and in three of those they coordinated on the efficient equilibrium.

In addition, in all the sessions that ended up at a minimum of 1 , the minimum was higher at least through a group size of 9. This higher level of efficiency for groups of up to size 9 is surprising in light of the fact that the minimum was always 1 for the large groups (8 or larger) in Table 2. ${ }^{19}$ Thus, there is clear support for the hypothesis that starting with a two-person group, which can reliably reach efficiency, and then adding informed players at a slow rate enables more efficient coordination than starting with a large group.

An equally important result is that growth does not work in the three no-history sessions (10 to 12). In all of these sessions, the minimum fell below 7 by the time the group reached a size of 4 and the minimum equaled 1 by the time the group reached a size of 8 . Moreover, this failure

\footnotetext{
${ }^{19}$ While Table 2 reports the fifth-period minima, the first-period minima in previous experiments were not as high as in the sessions reported here, and there was never a minimum of 7 . Note that in the control sessions, the minimum was never above 4.
}

was never driven entirely by only one subject-in every session, at least 6 of the 10 entrants chose a number below 7 in their first play. $^{20}$

To test directly whether growth with history results in higher minima, we need to compare choices in the control and no-history sessions with those in the history sessions. Table 4 compares the distributions of subject choices in the five control sessions, the three no-history sessions, and the nine history sessions in the fourth period in which participants played at a group size of $12 .^{21}$

\footnotetext{
${ }^{20}$ Overall, there appears to be a relationship between changes in group size and decreases in the minimum. Of the 34 total decreases, 24 (71 percent) coincided with an increase in group size, 6 (18 percent) occurred after the group reached a size of 12 (see footnote 18 ), 3 (9 percent) occurred before the growth process began, and one ( 3 percent) occurred during a "pause" in growth. These percentages do not differ significantly between the history and no-history sessions.

${ }^{21}$ A reasonable comparison is to compare the control groups in period $t$ with the $t$-th period in which the grown groups played as groups of size 12 . The analysis here sets $t=4$, because this is the greatest value of $t$ for which there are data in all the growth sessions.
} 
Table 4-Distributions of Subject Choices in Fourth PERIOD AS 12-PERSON GRoups

\begin{tabular}{lcccc}
\hline \hline Choice & & & $\begin{array}{c}\text { Growth } \\
\text { and } \\
\text { history }\end{array}$ & $\begin{array}{c}\text { Growth } \\
\text { and no } \\
\text { history }\end{array}$ \\
\hline & 7 & $3(5 \%)$ & $32(30 \%)$ & $0(0 \%)$ \\
& 6 & $0(0 \%)$ & $3(3 \%)$ & $0(0 \%)$ \\
& 5 & $6(10 \%)$ & $13(12 \%)$ & $0(0 \%)$ \\
& 4 & $22(37 \%)$ & $8(7 \%)$ & $0(0 \%)$ \\
& 3 & $7(12 \%)$ & $10(9 \%)$ & $0(0 \%)$ \\
& 2 & $9(15 \%)$ & $9(8 \%)$ & $1(3 \%)$ \\
Total & 1 & $13(22 \%)$ & $33(31 \%)$ & $35(97 \%)$ \\
\hline Minima & \multicolumn{5}{c}{60} & 108 & 36 \\
& \multicolumn{5}{c}{$1,1,1}$, & $1,1,1$, & $1,1,1$ \\
& \multicolumn{5}{c}{1,4} & $5,7,7$ & \\
\hline
\end{tabular}

The frequency of subjects choosing 1 was high in all three conditions (13 of 60 in the control; 35 of 36 in no history; 33 of 108 in history), but was clearly highest in the nohistory condition. While the proportion was higher for history sessions than for the control, this is not surprising since in three of the nine history sessions the minimum was 1 even before the group reached a size of 12 . In these groups there were more previous periods for subjects' choices to converge toward the inefficient equilibrium than in the control. ${ }^{22}$

Just as interesting, however, is the difference in the frequency with which subjects choose 7 . In the control and no-history sessions, only 3 of 60 (5 percent) and 0 of 36 ( 0 percent), respectively, did so. However, 32 of 108 subjects (30 percent) in the history sessions chose 7 . Therefore, the number of subjects playing the strategy corresponding to the efficient equilibrium was much higher in the grown groups than in the control sessions. The distributions of choices in the history condition and the two other conditions are significantly different in a one-tailed Kolmogorov-Smirnov test $(\mathrm{C}-\mathrm{H}: D=0.294$, $p<0.001$; NH-H: $D=0.667, p<0.001)$. A comparison of the mean choice in the history condition (3.89) with the mean choices in the

${ }^{22}$ This aspect of the comparison works against the hypothesis that growth works, since choices in unsuccessfully grown groups are usually almost all 1 , even prior to the first period as a 12-person group. control (3.18) and no-history (1.02) conditions using a one-tailed $t$-test (with unequal variances) also produces significant differences $\left(\mathrm{C}-\mathrm{H}: t_{161.78}=1.99, p<0.02 ; \mathrm{NH}-\mathrm{H}:\right.$ $\left.t_{109.88}=11.94, p<0.001\right)^{23}$

The tests above rely on the assumption that each choice is an independent observation, which is doubtful since subjects in a session are influenced by a shared history. Therefore, the level of significance reported by the statistics is exaggerated. One way to address this problem is to treat each session as the independent unit of analysis and examine only the minima. These minima are reported in the final row of Table 4. Note that the fourth-period minimum in all but one of the control sessions and no-history sessions was 1 . While the minimum in four of the history sessions was also 1 , the minimum was greater than 1 in the remaining five sessions. Moreover, the history sessions produced minima of at least 5 three times, which never occurred in the control sessions. A one-tailed Mann-Whitney $U$ test of the minima reveals significant differences between control and history sessions $(z=1.33, p<0.1)$ and no-history and history sessions $(z=1.55, p<0.07)$, and no difference between the control and nohistory sessions $(z=0.78)$. While the $p$-values in the tests above are not highly significant, this test is extremely conservative since it treats each group of 12 subjects as just one observation.

\section{Conclusion}

The experiment above shows that growth and exposure of entrants to history can alleviate the problem of large group coordination failure. The history sessions regularly produce independent 12-person groups coordinated at higher minima than 1 (including minima of 7), a result that has never been found in previous experi-

\footnotetext{
${ }^{23}$ The difference between the control and no-history conditions is also significant in two-tailed versions of the same tests $\left(t_{61.09}=10.28, p<0.001 ; D: 0.756, p<0.001\right)$. This is largely due to the fact that by the fourth period at a size of 12 , groups in the no-history condition are almost perfectly coordinated on the minimum choice of 1 .
} 
ments on minimum-effort coordination games. ${ }^{24}$ Growth, however, does not always work, and even groups that were grown slowly with exposure of entrants to history did not always remain coordinated efficiently.

Further evidence of successful growth can be seen in Weber (2005), which reports an experiment in which a subject in the role of "manager" decided how to grow the group in each session. In all four sessions, managers initially grew the group too quickly, resulting in a drop in the minimum. ${ }^{25}$ However, two of the four managers then started over and succeeded in growing their groups more slowly, resulting in groups of size 12 coordinated on high minima (6 and 7). The results of these two sessions also suggest that a better approach to growth than the rigid growth paths used in this paper might be one in which a manager waits until some set of conditions is met before growing. The fact that both of these sessions produced successful growth points to the potential value of such endogenous rules.

Another interesting result of the experiment reported here was unintended but merits mention. In one session (session 1) subjects appeared to form norms about how to react, not only to the previous minimum, but also to what happened in previous experiences with growth. In this session, the group appeared to develop a precedent that "when the group grows, the minimum falls by 1." In fact, in later periods several group members anticipated this change in the minimum and adjusted their behavior accordingly. ${ }^{26}$ This result suggests that players may form "higher-order" precedents based not just on levels of previous play (e.g., "expect the

\footnotetext{
${ }^{24}$ Another way to view this result is as a demonstration of transfer across games, from $n$-person games to similar $n+1$-person games (cf. Camerer and Knez, 2000; David Cooper and John Kagel, 2004).

${ }^{25}$ This indicates that the rate of growth might affect the success of growth. In addition, it also indicates that the need for slow growth might not be immediately apparent to people deciding how fast groups should grow.

${ }^{26}$ This phenomenon is even more striking in one of the endogenously grown sessions in Weber (2005), in which the group developed a norm that "the minimum falls every time the group grows, but in every period in which the group does not grow the minimum rises by exactly 1 ." All 12 subjects acted in precise concordance with the rule in later periods.
}

previous minimum to be the minimum again"), but also on the relation between levels of previous play and group sizes or transitions. That is, previous experience with growth may affect how group members subsequently jointly react to a similar event.

The main result in this paper-that slow growth coupled with the exposure of entrants to a group's history might be one reason why we observe large, successfully coordinated groups in the real world-can be extended to provide prescriptions for more efficient coordination in groups and firms outside the laboratory. For instance, the success of growth is linked to the exposure of entrants to the group's history, which can be thought of as a form of the training or acculturation that new members of an organization frequently undergo (see Noel Tichy, 2001).

Of course, the results also reveal that even slow growth and acculturation of new entrants can fail. Moreover, the results in this paper do not provide a prescription for how a group that is already large and coordinated on an inefficient equilibrium might turn things around. No doubt, in practice there are other ways to improve coordination in large groups. ${ }^{27}$ Nonetheless, the results address the important question of how groups can reach a large size while remaining efficiently coordinated.

\section{REFERENCES}

Arrow, Kenneth J. The limits of organization. New York: W. W. Norton \& Company, 1974. Berninghaus, Siegfried and Ehrhart, Karl. "Time Horizon and Equilibrium Selection in Tacit Coordination Games." Journal of Economic Behavior and Organization, 1998, 37(2), pp. 231-48.

Bornstein, Gary; Gneezy, Uri and Nagel, Rosemarie. "The Effect of Intergroup Competition on Group Coordination: An Experimental Study." Games and Economic Behavior, 2002, 41(1), pp. 1-25.

Brandts, Jordi and Cooper, David J. "A Change

${ }^{27}$ For instance, management might temporarily modify payoffs to change the game to one in which efficient coordination is easier (see Jordi Brandts and Cooper, forthcoming). 
Would Do You Good: An Experimental Study of How to Overcome Coordination Failure in Organizations." American Economic Review (forthcoming).

Cachon, Gerard P. and Camerer, Colin F. "LossAvoidance and Forward Induction in Experimental Coordination Games." Quarterly Journal of Economics, 1996, 111(1), pp. 165-94.

Camerer, Colin F. and Knez, Marc. "Coordination in Organizations: A Game-Theoretic Perspective," in Zur Shapiro, ed., Organizational decision making. Cambridge: Cambridge University Press, 1997, pp. 158-88.

Camerer, Colin F. and Knez, Marc. "Increasing Cooperation in Social Dilemmas by Establishing a Precedent of Efficiency in Coordination Games." Organizational Behavior and Human Decision Processes, 2000, 82(2), pp. 194-216.

Charness, Gary. "Self-Serving Cheap Talk: A Test of Aumann's Conjecture." Games and Economic Behavior, 2000, 33(2), pp. 177-94.

Chaudhuri, Ananish; Schotter, Andrew and Sopher, Barry. "Talking Ourselves to Efficiency: Coordination in Inter-Generational Minimum Games with Private, Almost Common and Common Knowledge of Advice." New York University, C. V. Starr Center for Applied Economics Working Papers: No. 0111, 2001.

Coase, Ronald H. "The Nature of the Firm." Econometrica, 1937, 4(16), pp. 386-405.

Cooper, David and Kagel, John. "Learning and Transfer in Signaling Games." Unpublished Paper, 2004.

Cooper, Russell W. Coordination games: Complementarities and macroeconomics. Cambridge: Cambridge University Press, 1999.

Crawford, Vincent P. "Adaptive Dynamics in Coordination Games." Econometrica, 1995, 63(1), pp. 103-43.

Gittell, Jody H. "Supervisory Span, Relational
Coordination and Flight Departure Performance: A Reassessment of Postbureaucracy Theory." Organization Science, 2001, 12(4), pp. $468-\overline{83}$.

Hirshleifer, Jack. "From Weakest-Link to BestShot: The Voluntary Provision of Public Goods." Public Choice, 1983, 41(3), pp. 371-86.

Knez, Marc and Camerer, Colin F. "Creating Expectational Assets in the Laboratory: Coordination in Weakest-Link Games." Strategic Management Journal, 1994, 15(8), pp. 101-19.

March, James G. and Simon, Herbert A. Organizations. New York: John Wiley \& Sons, 1958.

Nanda, Ashish. "Implementing Organizational Change," in Miguel Pina e Cunha and Carlos Alves Marques, eds., Organizational change in a changing context. Lisbon: ISPA, 1999, pp. 489-522.

Schelling, Thomas C. The strategy of conflict. Cambridge, MA: Harvard University Press, 1960.

Tichy, Noel. "No Ordinary Boot Camp." Harvard Business Review, 2001, 79(4), pp. 6370.

Van Huyck, John B.; Battalio, Raymond C. and Beil, Richard O. "Tacit Coordination Games, Strategic Uncertainty, and Coordination Failure." American Economic Review, 1990, 80(1), pp. 234-48.

Weber, Roberto A. "Interdependence in Organizations and Laboratory Groups," PhD diss., California Institute of Technology, 2000.

Weber, Roberto A. "Managing Growth to Achieve Efficient Coordination: Theory and Experimental Evidence." Unpublished Paper.

Weber, Roberto A.; Camerer, Colin F.; Rottenstreich, Yuval and Knez, Marc. "The Illusion of Leadership: Misattribution of Cause in Coordination Games." Organization Science, 2001, 12(5), pp. 582-98. 